\title{
Dissemination of Technical Assistance Information
}




\section{INTERNATIONAL MONETARY FUND \\ DiSSEMINATION OF TECHNICAL ASSISTANCE INFORMATION}

Prepared by the Office of Technical Assistance Management and the Legal Department

(In consultation with other Departments)

Approved by Alfred Kammer and Sean Hagan

April 3, 2008

\section{INTRODUCTION}

1. This paper sets out a framework for streamlined and strengthened procedures for the wider dissemination of technical assistance-related information ("TA Information"). On the basis of this framework, management intends to issue guidelines to the staff setting forth these new procedures. Management further intends to publish these guidelines on the Fund's external website and to take steps to bring them to the attention of members and other recipients of Fund TA.

\section{BACKGROUND}

\section{Within the Fund, TA information is held by staff and management, and the} general practice has been to treat most $\mathrm{TA}$ information as confidential. ${ }^{1}$ Staff and management may, under agreed conditions, share such information with a limited group of recipients within the Fund (in particular with the Executive Board) and outside the Fund (in particular, with donors and other TA providers).

3. Notwithstanding the general practice regarding confidentiality, over the years, a number of specific rules for the dissemination of different types of $\mathrm{TA}$ information for specific situations have evolved. For instance, the sharing of TA reports with the World

\footnotetext{
${ }^{1}$ See Exchange of Documents with Other International Agencies-Release of Technical Assistance Reports and Modification of Procedures for Release of Documents ("Exchange of Documents with Other IA", 1/28/93), in http://www.imf.org/external/pubs/ft/sd/index.asp?decision=9786-(93/20) p. 2, in which staff observed: "Since its inception, technical assistance by the Fund has always been provided on a highly confidential basis."; "Annual Report on Technical Assistance" (the "2000 Report on TA", 10/05/2000) in http://www.imf.org/external/pubs/ft/arta/2000/eng/ para. 93, stating that Fund TA is sought on a confidential basis and therefore TA recipients have the right to decide on dissemination, subject to management approval.
} 
Bank is governed by special regimes, including those stemming from the Fund-Bank Concordat $^{2}$ and the FSAP Confidentiality Protocol. ${ }^{3}$ Similarly, in 1993, under the Transmittal Policy, the Board approved separate procedures for the distribution of TA reports to international organizations meeting certain criteria. ${ }^{4}$ The proliferation of specific rules for various situations, which are addressed in greater detail below, has given rise to a patchwork of overlapping policies and practices. In some cases, the resultant uncertainties have been further exacerbated by different interpretations of such policies and practices by staff in different departments. As a consequence, rather than promoting greater transparency of TA information, the lack of clarity under the current dissemination framework may in fact be inhibiting the wider sharing of TA information, both within and outside of the Fund.

\section{For a number of reasons, TA information should be disseminated more widely.} The more active sharing of TA information with donors and other TA providers would improve coordination, exploit synergies, and enable the Fund to prioritize and leverage its limited TA resources, ${ }^{5}$ thereby fulfilling key objectives under the Paris Declaration on Aid Effectiveness. ${ }^{6}$ Moreover, especially from the perspective of their own accountability to their governments and legislators, donors to the Fund's TA program have a legitimate interest in receiving information on TA that is financed by them. Within TA recipient countries, the wider dissemination of TA information among different government agencies would

\footnotetext{
2 "Bank-Fund Collaboration in Assisting member Countries" ("The IMF-World Bank Concordat", Rev. 3, 3/31/1989), available at http://www.imf.org/external/pubs/ft/sd/index.asp?decision=DN12
}

\footnotetext{
${ }^{3}$ See "Confidentiality Protocol—Protection of Sensitive Information in the Financial Sector Assessment Program”, Selected Decisions, Thirty-Second Issue, page 108.

${ }^{4}$ These criteria include commonality of operational interest, need for the TA information, reciprocity of document exchanges, and assurances of confidentiality. See the 1993 decision on Exchange of Documents with Other International Agencies (the "1993 Decision") in http://www.imf.org/external/pubs/ft/sd/index.asp?decision=9786-(93/20).
}

${ }^{5}$ See "Policy Statement on IMF Technical Assistance" (the "2000 Policy Statement", Rev. 2, 3/24/2000) in http://www.imf.org/external/pubs/ft/psta/ , p.3; "Summing Up by the Acting Chairman on Review of FY 2000 Annual Technical Assistance Report and Discussion on Alignment of Technical Assistance with the IMF's Policy Priorities" (1/10/2001), pp. 2, 4, and "Ensuring Alignment of Technical Assistance with the IMF's Policy Priorities" (12/20/2000), pp. 14-22, documents available under the Fund's Archives Policy,; See also PIN No. 02/73 (July 18, 2002) in http://www.imf.org/external/np/sec/pn/2002/pn0273.htm, and "Review of Technical Assistance Policy and Experience" (the "2002 Review of TA Policy and Experience" 6/13/2002) available at http://www.imf.org/external/np/ta/2002/eng/061202.htm, pp. 39-40, 47.

${ }^{6}$ For example, paragraph 32 of the Paris Declaration calls for donors to "work together to reduce the number of separate, duplicative, missions to the field and diagnostic reviews," while paragraph 35 advocates a "full use of their respective comparative advantage at sector or country level by delegating, where appropriate, authority to lead donors for the execution of programmes, activities and tasks."

See http://www.oecd.org/document/18/0,2340,en_2649_3236398_35401554_1_1_1_1,00.html. 
strengthen ownership and facilitate the more effective implementation of TA recommendations. ${ }^{7}$ More generally, through publication, the membership and the public at large would benefit from a better understanding of best practices, and the Fund's experiences in the provision of TA. ${ }^{8}$

\section{In recent years, the Executive Board has called for the wider dissemination of} TA information. Directors have welcomed the enhanced dissemination of TA reports, have emphasized the critical importance of sharing relevant information on a reciprocal basis with other TA providers and donors (especially those financing Fund TA), and have encouraged members to consent to the publication of TA reports on the Fund's external website. ${ }^{9}$ In this same line, the Independent Evaluation Office (IEO), the Managing Director's Task Force on Technical Assistance, and the Office of Internal Audit and Inspection (OIA) have also recommended the wider dissemination of TA information. ${ }^{10}$ Most recently, these recommendations have been echoed and reinforced in the Fund's Medium-Term Strategy, the Report of the External Review Committee on Bank-Fund Collaboration, and the Joint Management Action Plan (JMAP) for Enhancing Bank-Fund Collaboration. ${ }^{11}$

\section{At the same time, any move towards the wider dissemination of TA information should take into account the need to safeguard confidential information provided to Fund staff and the candidness of the staff's TA advice. ${ }^{12}$ Unless TA recipients have the}

\footnotetext{
7 "IEO Evaluation of the Technical Assistance Provided by the Fund-Volume I" (the "IEO Evaluation of IMF's TA", Vol.1, 1/31/05), p.78 available at http://www.imf.org/external/np/ieo/2005/ta/eng/013105.htm; "Conclusions of the Task Force on IMF Technical Assistance" ("Conclusions of the Task Force on IMF TA", 7/13/05), pp. 17-18 available at http:/www.imf.org/external/np/pp/eng/2005/071205.htm.

82000 Policy Statement, p. 7; PIN No. 02/73 (July 18, 2002), and the 2002 Review of TA Policy and Experience, pp. 45-46; "Summing Up by the Acting Chairman on the Review of Fund Technical Assistance" (6/15/1999), document available under the Fund's Archives Policy, p.3.

${ }^{9}$ PIN No. 04/21 (March 17, 2004) available at http://www.imf.org/external/np/sec/pn/2004/pn0421.htm ; PIN No. 02/73; "Summing Up by the Acting Chairman on the Review of the FY 2000 Annual Fund Technical Assistance" (January 10, 2001), p. 4; "Summing Up by the Acting Chairman on the Review of Fund Technical Assistance (June 15, 1999) p.3. These documents are available under the Fund's Archives Policy,

${ }^{10}$ IEO Evaluation of IMF's TA Vol.1, pp. 78-79, 82-83; Conclusions of the Task Force on IMF TA, pp. 17-18; "Review of Fund Technical Assistance" (5/17/99), document available under the Fund's Archives Policy, pp. 43-44.

11 See "Enhancing Collaboration-Joint Management Action Plan" (9/24/07) available at http://www.imf.org/external/np/pp/2007/eng/092007.pdf ,in particular Table 1, paragraph 15, respectively. See also Box 1 of "Enhancing the Impact of Fund Technical Assistance" (4/3/08).

12 PIN No. 02/73. See also PIN No. 04/21; "Summing Up by the Acting Chairman on the Review of the FY 2000 Annual Fund Technical Assistance" (January 10, 2001),p. 4; and "Summing Up by the Acting Chairman on the Review of Fund Technical Assistance (June 15, 1999) p.3.
} 
assurance that sensitive information provided to the staff in confidence would continue not to be disclosed, they might not be willing to ask for Fund TA. Moreover, with wider dissemination, there is the risk that staff could be less candid in their assessments and recommendations. ${ }^{13}$

7. To facilitate wider dissemination, the framework governing the disclosure of TA information, including TA reports, needs to be clarified and its implementation strengthened. The remainder of this paper describes the existing framework in Section II and discusses measures that would address identified weaknesses in Section III. Section IV provides some estimates on the resource implications of implementing these measures.

\section{EXISTING FRAMEWORK ON DISSEMINATION}

\section{A. Legal Basis for Provision of TA and Management Authority over TA Activities}

8. The Fund's authority to provide TA is set forth in Article V, Section 2(b) of the Articles of Agreement under which the Fund "may", upon request, provide technical services consistent with the purposes of the Fund. ${ }^{14}$ This authority is exercised by the Managing Director as part of the ordinary business of the Fund, but subject to relevant Executive Board decisions and guidance on general TA policy matters. Indeed, the Executive Board may, at any time, adopt decisions on general TA policy which will frame and guide management's authority over TA. ${ }^{15}$

9. Under the existing framework, the Managing Director may accept TA requests from members without the prior approval of the Executive Board. ${ }^{16}$ With respect to TA requests from non-member countries and international agencies, the advance approval of the Board is required before TA can be provided by staff. ${ }^{17}$ Subject to a few exceptions, management's authority over TA activities also extends to decisions on dissemination of TA reports and other TA information, including publication - that is, to the extent that Fund

\footnotetext{
132002 Review of TA Policy and Experience, pp. 47-48.

${ }^{14}$ Article V, Section 2(b) reads in pertinent part: "If requested, the Fund may decide to perform financial and technical services, including the administration of resources contributed by members, that are consistent with the purposes of the Fund."

${ }^{15}$ Examples of these general policy decisions adopted by the Board are the rules for effective prioritization of TA activities and the country contribution policy for technical assistance. See "Summing Up by the Acting Chairman on the Review of the FY 2000 Annual Fund Technical Assistance" (January 10, 2001), p. 2;

"Ensuring Alignment of Technical Assistance with the IMF's Policy Priorities" (12/20/00), Annex II and Supp. I, available under the Fund's Archives Policy; and the 2000 Policy Statement, Rev. 2, paragraph 16.

${ }^{16}$ See "Reduction and Streamlining of Board Documentation" (8/15/1991), available under the Fund's Archives Policy, p. 5.

17 "The advance approval of the Executive Board shall be necessary for technical services by persons on the staff of the Fund in response to requests by non-members or international agencies." Rule N-16(d) of the Fund's Rules and Regulations.
} 
consent is required to disseminate particular TA information, it is generally management who provides such consent. ${ }^{18}$

\section{B. Dissemination of Confidential Information}

10. The Fund's framework for the dissemination of TA information is based upon an important general rule respecting the disclosure of confidential information. As a general legal principle, Fund management and staff may not disclose information that a member or other party has provided to them in confidence, unless that party consents to such disclosure. ${ }^{19}$ A determination that particular information has been provided in confidence is based upon an examination of all the surrounding circumstances, including the nature of the information provided; at issue is the question whether there was an understanding between staff and the other party that such information would not be disclosed without that other party's consent. This understanding can be express or implied.

11. At the same time, there are limits on the ability of Fund management and staff to agree not to disclose particular information to the Executive Board. The Executive Board has put in place certain policies that effectively require Fund management and staff to disclose to the Board certain types of information. In circumstances where the Executive Board has established a policy requiring that certain information received from members be disclosed to the Executive Board, it is incumbent upon Fund management and staff to inform the member of this policy before the information is provided by the member. In this context, if the member provides the information, it is judged to be on notice that such information will not be held in confidence by management and staff vis-à-vis the Executive Board. For example, in the context of use of Fund's resources (UFR), this type of policy was established by the Executive Board in 1999 with respect to "side letters". ${ }^{20}$ While it was previously possible for Fund management not to disclose a side letter to the Board (e.g., because of confidential understandings reached between management and the authorities of a member country), these documents must now be disclosed to the Board under the conditions specified in the relevant Board decision.

12. In the context of technical assistance, Fund policy requires management to share with the Executive Board certain types of reports arising from Fund $\mathrm{TA}$ - that is, Reports on Standards and Codes (ROSCs) and Assessment of Financial Sector Supervision and Regulations (AFSSRs) - for the purposes of informing the Board's work on surveillance with the relevant members. Such sharing is required even though the

\footnotetext{
${ }^{18}$ Under internal procedures management has delegated decisions on dissemination to heads of departments.

${ }^{19}$ See, for example, the "Opening the Fund's Archives" in http://www.imf.org/external/pubs/ft/sd/index.asp?decision=11192-(96/2).

${ }^{20}$ See Decision No. 12067-(99/108) adopted September 22, 1999 available in http://www.imf.org/external/pubs/ft/sd/index.asp?decision=12067-(99/108), and "Side Letters and the Use of Fund Resources" (3/10/99) available under the Fund's Archives Policy, para. 23.
} 
relevant reports would otherwise be treated as confidential TA reports. ${ }^{21}$ As discussed above, members are on notice of the existence of these Fund policies and are effectively aware that the documents covered by these policies must be disclosed to the Executive Board by management (i.e., members are considered to have consented to such disclosure). Where a member requests a ROSC or an FSAP, it is presumed to do so in full knowledge of the relevant Fund policies and, accordingly is assumed to have consented to the disclosure provided for under these policies. ${ }^{22}$

\section{Dissemination of Various Categories of TA Information to Various Categories of Potential Recipients of Such Information}

\section{As referred to above, historically the practice has been that many types of TA information have been treated by Fund staff as confidential. ${ }^{23}$ This practice suggests that} there is an implicit understanding between Fund staff and the member that the information provided by the latter in the context of the provision of TA is confidential. For purposes of describing existing practice respecting the dissemination of TA information in more concrete terms, several types of TA information can be identified. ${ }^{24}$ These include: (i) the fact of TA provision and the subject matter of TA; (ii) details of the administration of TA projects; (iii) information, received or generated by Fund staff, that forms the basis of Fund TA advice; and (iv) final TA advice. ${ }^{25}$ Several types of potential recipients of TA information, within and outside the Fund, can also be identified. These are: (i) the TA recipient agency, staff within

\footnotetext{
${ }^{21}$ It should be noted, however, that even in circumstances where such information is required to be provided to the Board, confidentiality issues still remain. Specifically, the Executive Board may not publish information that it has received from a member on the understanding that it remain confidential vis-à-vis the public, unless the member consents.

${ }^{22}$ Under Article XII, Section 8, the Fund is also precluded from publishing its views (meaning the Executive Board's views) with regard to a member without the member's consent unless certain conditions are met. See "Legal Aspects of the Publication of Staff Reports on Article IV Consultations and Use of Fund Resources (3/29/1999) available under the Fund's Archives Policy. In the case of technical assistance, since the advice or views provided to members in specific cases comes from the staff, not from the Executive Board, the provisions of Article XII, Section 8 are rarely an issue. For this reason, the paper does not further address Article XII, Section 8 .

${ }^{23}$ See footnote 1 above.

${ }^{24}$ See "Exchange of Documents with Other IA" (1/28/93) in http://www.imf.org/external/pubs/ft/sd/index.asp?decision=9786-(93/20). pp. 2-3.
}

${ }^{25}$ The guidelines to be issued by management will describe in more detail the specific types of TA information covered by the new procedures. The dissemination of information under the Financial Sector Assessment Program (FSAP) - which is a form of technical assistance — is not discussed in this paper as the handling of such information is subject to a separate regime reflecting understandings reached between the managements of the Fund and the World Bank. See "Confidentiality Protocol—Protection of Sensitive Information in the Financial Sector Assessment Program”, Selected Decisions, Thirty-Second Issue, p. 108. 
the TA-receiving agency and other relevant agencies within the country of the TA recipient; (ii) Executive Directors; (iii) donors and other TA providers; and (iv) the general public.

\section{Fact of TA Provision and Subject-Matter of TA}

14. It has generally been the practice of Fund staff to disclose to the Executive Board and to parties outside the Fund the fact that the Fund is providing TA to a particular party and to describe the subject matter of that TA. While such information has not been disclosed whenever the TA recipient has specifically requested that it be kept confidential, Fund staff has generally otherwise assumed that the TA recipient consents to disclosure. Indeed this information is routinely provided in summary form to the Executive Board in annexes attached to Article IV consultation or UFR staff reports. Such information has also been generally provided to donors and other TA providers without Fund staff seeking the TA recipient's consent.

\section{Administration of $T A$}

\section{Information on the administration of individual TA projects is not generally} disclosed by Fund staff. This information includes the project framework, monitoring and evaluation matters, budget figures, and timing of missions. Such information seldom involves understandings of confidentiality with the TA recipient but may include confidential information respecting other parties (e.g., the terms of employment of a TA expert). In any event, such details are typically not made available to the Executive Board or published. ${ }^{26}$ In disclosing such information to donors and other TA providers, the practice of Fund departments has not been uniform. In some cases, such information has, for coordination purposes, been disclosed by staff to other TA providers, with due regard for any relevant confidentiality considerations. In other cases, Fund departments have simply declined to make this information available.

\section{Information Forming the Basis of TA Advice}

16. Information that may be provided to the staff or that is generated by staff in the course of provision of TA constitutes a third category of TA information. This category includes information received from the authorities or other parties that is used as a basis for the provision of TA advice and staff's analysis of such information, including drafts of the TA advice which Fund staff ultimately provides. Such information may or may not be provided to staff on a confidential basis. In some cases, this information could be highly sensitive (e.g., information from a central bank on foreign exchange operations) while, in

\footnotetext{
${ }^{26}$ However, under the Fund's TA Evaluation Program, the results of TA project evaluations are reported to the Board on an annual basis. See Technical Assistance Evaluation Program-Findings of Evaluations and Updated Program (Revision 1), 11/6/06 available at http://www.imf.org/external/np/ta/2004/eng/030104.htm for the latest report under the evaluation program.
} 
other cases, it would not be subject to confidentiality concerns. In either case, this information is not currently shared with the Executive Board, TA providers and other donors, or the public.

\section{Final TA Advice}

17. The fourth category of TA information is final TA advice conveyed by Fund staff to the recipient of $\mathrm{TA}$ in the form of $\mathrm{TA}$ reports, other final documents such as draft legislation or aide-mémoires, e-mails or orally. TA reports and other types of final TA advice (hereinafter collectively referred to as "TA reports") have been invariably treated as confidential, ${ }^{27}$ requiring the consent of the recipient of Fund TA prior to their dissemination, even when they contain no actual information that a member or other party has provided on a confidential basis. Paragraphs 18-23 below discuss the rules applicable to the dissemination of TA reports to the various potential recipients of such reports.

18. The long standing practice of treating TA reports as confidential was recognized by the Executive Board in its 2000 Policy Statement on TA, effectively establishing this practice as a matter of Fund policy. ${ }^{28}{ }^{29}$ TA reports are subject to specific rules that the Executive Board and Fund management have put in place in order to govern their disclosure. In this regard, the dissemination of TA reports is typically limited to staff, the authorities of the member, the member's Executive Director, and the World Bank. ${ }^{30}$ The consent of the TA recipient is required prior to the dissemination of TA reports to the Executive Board, other TA providers and donors other than the World Bank, or the general public. ${ }^{31}$

\section{The duty of confidentiality inhibits the dissemination of TA reports within the}

member country. This is because the duty of confidentiality is owed to the direct recipient of TA and, accordingly, Fund staff requires the consent of the TA recipient before disseminating TA reports to other agencies of government within the member country. TA reports are, therefore, in many cases not disseminated to other agencies within the member

\footnotetext{
27 "Statement on the Review of Fund Technical Assistance and Suggested Issues for Discussion" (5/17/1999), p. 22.

28 “2000 Policy Statement”, Rev. 2, (3/24/2000), pp. 7-8.

${ }^{29}$ The manner in which the Fund treats the dissemination of documents containing information received from member countries is not unique to TA information. Outside the context of TA, the Fund has also a long standing practice of treating documents containing information provided by member countries as confidential, even if no actual information was provided on a confidential basis. This is the case for instance with staff reports issued to the Board in the context of UFR and surveillance, where the publication or dissemination of such staff reports are subject to the consent of the relevant member country whether or not they actually contain information provided on a confidential basis.

30 , "Statement on the Review of Fund Technical Assistance and Suggested Issues for Discussion" (5/17/1999), p.21-22.

31 “2000 Policy Statement”, Rev. 2, (3/24/2000), para. 20. It has been the practice of the Fund to allow TA recipients to withdraw consent at any time prior to dissemination of the TA report.
} 
country that may be called upon to participate in the implementation of TA recommendations. Moreover, even within the recipient agency itself, TA reports often do not reach technical level staff as reports are generally only delivered by Fund staff to high-level officials. $^{32}$ The Managing Director's Task Force on TA, echoing the IEO, has emphasized that the chances for implementation of TA recommendations could be increased if TA reports were made available to technical staff. ${ }^{33}$ The Task Force has thus proposed that staff should systematically seek the authorities' consent to disseminate TA reports directly to technical staff. ${ }^{34}$

\section{Access by Executive Directors and members of their staff to TA reports is}

restricted. Although such access has improved since the procedures established by management in 2002, the consent of TA recipients is still required. ${ }^{35}$ While letters transmitting finalized TA reports to the authorities request their consent to make TA reports available to Executive Directors and members of their staff within 60 days of transmittal, the authorities often fail to respond to these requests. ${ }^{36}$ In this regard, the Managing Director's Task Force on TA has proposed that departments proactively seek the authorities' consent both at the beginning of TA missions and at the time of transmittal of TA reports. ${ }^{37}$

\section{The rules governing the dissemination of TA reports to donors and TA} providers distinguish between the World Bank and other agencies. While a regime similar to the one for Executive Directors applies to the disclosure of TA reports to donors and TA providers other than the World Bank, ${ }^{38}$ a special regime applies to the disclosure of TA reports to World Bank staff. This special regime stems from the Concordat (SM/89/54, Rev. 1) on Bank-Fund Collaboration, which calls for the exchange of TA reports between staffs of both institutions. ${ }^{39}$ Under long-standing procedures, TA reports are provided to Bank staff upon request, without need for Fund staff to obtain the explicit consent of the TA

\footnotetext{
32 "IEO Evaluation of IMF's TA, Vol.1, (1/31/05), paras. 144-145, and 154; “Conclusions of the Task Force on IMF TA”, (7/13/05), paras. 8 and 32.

33 “Conclusions of the Task Force on IMF TA", (7/13/05),para. 32.

${ }^{34}$ Id.

${ }^{35}$ For this reason, TA reports are not routinely circulated to the Executive Board and, with respect to publication, are not governed by the provisions of the Fund's Transparency Policy Decision, adopted October 5, 2005 available at http://www.imf.org/external/pubs/ft/sd/index.asp?decision=13564-(05/85). However, as an operational matter, if and when a member consents to publication of a TA report that is not of the type routinely circulated to the Executive Board, then prior to publication on the Fund's website, the TA report is circulated to the Board for its information.

${ }^{36}$ The request for consent is brought to the attention of the relevant Executive Director.

37 “Conclusions of the Task Force on IMF TA”, (7/13/05), para. 33.

38 This is in accordance with internal procedures for availability of TA reports.

${ }^{39}$ See, for example, "Report of the Managing Director and the President on Bank-Fund Collaboration" (Rev. 1, 9/25/1998), available under the Funds' Archives Policy, para. 30.
} 
recipient. ${ }^{40}$ As the procedures stemming from the Fund-Bank Concordat have been made available to the Fund's membership in various contexts, Fund members have been placed on notice that TA reports will be shared with Bank staff and, in requesting Fund TA in full knowledge of these rules, are presumed to have implicitly consented to such disclosure. Since 2000, the Fund's TA Policy Statement makes it clear that TA reports may be provided to the World Bank without the need for obtaining the TA recipients' explicit consent.

22. Even within Fund staff, access to TA reports is restricted. Access by staff to TA reports is governed by procedures established by management in 2002 . Under these procedures, all finalized TA reports, except those classified as "STRICTLY CONFIDENTIAL" and FSAP Reports, are forwarded to the Institutional Repository. ${ }^{41}$ Of the TA reports that are forwarded to the Institutional Repository, those that are classified "FOR OFFICIAL USE ONLY" are accessible to all staff, while TA reports classified "CONFIDENTIAL" are accessible to a smaller group of staff, as determined in GAO 35. ${ }^{42}$ TA reports classified "CONFIDENTIAL" will be reclassified automatically "FOR OFFICIAL USE ONLY" after two years, unless the authoring department or the relevant area department considers that the sensitivity of the information has not sufficiently diminished. ${ }^{43}$

23. Access by the general public to TA reports is very limited. They are made available to the general public either through the Archives Policy after 20 years, or through publication. In practice, both avenues of access are rarely used. To foster the wider sharing of lessons learned from the TA experience, the Executive Board has urged TA recipients to consent to the voluntary publication of TA reports on the Fund's external website, with appropriate regard paid to issues of confidentiality. ${ }^{44}$ In response, the Managing Director's Task Force on TA has recommended that departments proactively encourage TA recipients to consider publication on the Fund's external website. ${ }^{45}$

\section{In addition to the rules described in paragraphs 18-23 above, the Executive Board has established a number of policies affecting the dissemination of TA reports in particular situations.}

\footnotetext{
40 "Review of Fund Technical Assistance”, p. 20; “2000 Policy Statement”, para. 20. However, as with other documents shared with Bank staff pursuant to the Fund-Bank Concordat, Fund staff retain discretion as to whether any particular TA report should be shared. In this regard, Departments usually consult with the authorities prior to sharing TA reports with Bank staff. In any case, to the extent a member objected to the sharing with Bank staff of a particular TA report, Fund staff would respect the authorities' wishes.

${ }^{41}$ In accordance with internal procedures.

${ }^{42} \underline{\text { Id. }}$. Under internal procedures TA documents may be classified within three categories, "FOR OFFICIAL USE ONLY", “CONFIDENTIAL”, and "STRICTLY CONFIDENTIAL".

${ }^{43}$ In accordance with internal procedures.

44 PIN No. 04/21 (March 17, 2004);

45 "Conclusions of the Task Force on IMF TA", (7/13/05), para. 33.
} 
- In the context of surveillance, the Board has decided that Reports on the Observance of Standards and Codes (ROSCs) and Assessment of Financial Sector Supervision and Regulation (AFSSRs) be circulated to the Executive Board as background information for Article IV consultations. ${ }^{46} 47$

- $\quad$ The Executive Board has also put in place the Transmittal Policy which governs the routine transmittal (i.e., on a regular basis) of certain types of reports (including TA reports) to certain international agencies that meet specified criteria (i.e., commonality of operational interests, reciprocal transmittal of comparable documents to the Fund, and confidentiality safeguards). ${ }^{48}$ The Transmittal Policy has rarely been used for routine transmission of TA reports because, unlike UFR and Article IV consultation reports, TA reports are not produced on a regular basis. ${ }^{49}$ In addition, some TA providers and donors may not qualify as "international agencies" within the

\footnotetext{
${ }^{46}$ Since September 1999 completed ROSC modules have been circulated to the Board as supporting documentation for Article IV Consultations, see "Assessing the Implementation of Standards-A Review of Experience and Next Steps" (1/12/2001) available at http://www.imf.org/external/np/pdr/sac/2001/eng/review.pdf, para. 15 and Box 2. In November 2003, OFCs Module 2, Main Reports were reclassified as "staff reports" (Assessment of Financial Sector Supervision and Regulation Reports-AFSSRs) to be circulated to the Executive Board, see "Offshore Financial Centers-The Assessment Program - Report and the Future of the Program" (8/4/2003), available at http://www.imf.org/external/np/mae/oshore/2003/eng/073103.htm para. 41 (first bullet point), and “Acting Chair's Summing Up on Offshore Financial Centers-The Assessment Program-A Progress Report and the Future of the Program" (PIN No. 03/138, November 24, 2003) available at http://www.imf.org/external/np/sec/pn/2003/pn03138.htm
}

\footnotetext{
${ }^{47}$ Although these reports are, by nature, TA reports, to allow for their circulation to the Executive Board, they were re-classified as Board documents, that is, as staff reports prepared to be circulated to the Board. Fund members are effectively on notice that the information contained in these reports, even if confidential, will be shared with the Board. Furthermore, as these reports are Board documents, they can only be published with the approval of the Executive Board. In this context, the Board decided that these reports be subject to the Transparency Policy Decision and, pursuant to that decision, may be published by the Fund upon consent of the concerned member. See Transparency Decision available at http://www.imf.org/external/pubs/ft/sd/index.asp?decision=13564-(05/85)
}

\footnotetext{
${ }^{48}$ See the "1993 Decision" available at http://www.imf.org/external/pubs/ft/sd/index.asp?decision=9786(93/20), as amended .

${ }^{49}$ Prior to the changes introduced in 1993, the transmittal of TA reports took place on an ad hoc basis. An example is the ad hoc request for transmittal of a TA report to the OECD approved by the Board in a 1986.
} 
meaning of the policy, and the criterion on commonality of operational interest may be difficult to meet. ${ }^{50}$

- Under the Archives Policy, TA reports over 20 years old are available to outside persons upon request, provided that reports originally classified "Strictly Confidential" may not be released if the Managing Director finds that the material remains highly confidential or sensitive. ${ }^{51}$

\section{STREnGTHENEd FrameWORK FOR DisSEMinAtion}

\section{A. Shortcomings of Existing Framework}

\section{The discussion in Section II suggests a number of areas where the framework governing the dissemination of TA information could be clarified and strengthened. Specifically, the following areas need to be addressed:}

- $\quad$ There are varying practices among departments regarding disclosure to the Executive Board, other TA providers and donors, and the public of information respecting: (i) the fact of provision of TA and its general subject matter; and (ii) the administration of TA projects. These practices need to be unified on a Fund-wide basis.

- $\quad$ The authorities often fail to respond to staff requests to consent to make TA reports available to Executive Directors and to other TA providers and donors. In this regard, the 2002 procedures instituted by management - in part to make TA reports more widely available to Executive Directors and other TA providers and donors- have not worked as well as envisaged. In particular, experience indicates that country authorities typically fail to respond to staff requests for consent to make TA reports available to Executive Directors, other TA providers, and donors. For example, out of 248 TA reports finalized in FY 2007 by TA departments and for which consent to release was sought from TA recipients, responses were received in only 35 cases (14 percent). Importantly, there were only 4 actual refusals to disseminate TA reports. Yet, the practice of requiring explicit consent has effectively precluded the release of

\footnotetext{
${ }^{50}$ In applying the policy, the Fund has made these documents available to "international organizations", i.e., entities established by treaty or other legal instrument under international law with a legal personality and will independent of their constituent members. With regard to the criterion on commonality of operational interest, qualifying international agencies would be those that "share with the Fund a current operational and financial interest in the particular member country concerned", particularly those that "are or will be providing substantial financial assistance to Fund members, primarily balance of payments support whose effectiveness is dependent on the macroeconomic environment".

${ }^{51}$ See "Opening the Fund's Archives" in http://www.imf.org/external/pubs/ft/sd/index.asp?decision=11192$\underline{(96 / 2)}$
} 
the vast majority of reports, even though they may not contain any confidential information.

- $\quad$ There should be greater sharing of TA information with other TA providers and donors, to facilitate and enhance donor coordination. Further, donors that finance Fund TA would also have a special interest in receiving information on the projects that they fund.

- $\quad$ The public in general has very limited access to TA reports. Very few TA reports are published on the Fund's website. The low rate of publication of TA reports limits the dissemination of best practices and experiences in key areas of capacity building.

- $\quad$ The Fund's current regime for the dissemination of TA reports is not entirely consistent with the policies and practices of comparable international organizations (see Annex I).

26. More importantly, the entire framework for the dissemination of TA information is based upon the need to obtain the consent of the $T A$ recipient to the disclosure of confidential information. Thus far, the Fund has relied upon a number of procedures to obtain such consent either explicitly or implicitly. Moving forward, other ways to obtain such consent could be considered, as discussed below.

\section{B. Management's Intentions for a Strengthened Framework}

27. Given the need for wider dissemination of TA information, management intends to implement the framework outlined below. On the basis of this framework, new procedures will be set out in guidelines to be issued by management on the dissemination of TA information. These guidelines will be published on the Fund's external website. In addition, the Secretary's Department will send a communication to all members attaching the guidelines when they have been finalized. As is explained below, the framework would provide for the wider and more systematic dissemination of TA information and would effectively assume that the relevant TA recipient consents to such dissemination unless the TA recipient explicitly objects. Through the Fund's publication of the guidelines, members and other potential TA recipients would be placed on notice that, in requesting Fund TA in full knowledge of these guidelines, they will be deemed to have consented to dissemination unless they explicitly object. Staff will also be reminded that, when responding to any particular TA request, they should alert the requesting entities of the content of the guidelines. The adoption of the strengthened procedures set forth below is within the authority of management; no decision of the Executive Board is required.

\section{Information Related to the Fact of TA Provision and Subject-Matter of TA}

28. In the proposed guidelines to staff on the dissemination of TA information, management will explicitly clarify that the fact of provision of Fund TA in response to a particular TA request and the general subject matter of that $T A$ will not be considered confidential information, unless the TA recipient specifically indicates otherwise. This information would thus be ordinarily made available to the Executive Directors, TA 
providers and donors, and the general public. In those cases where the TA recipient might not want such information to be made available, particularly to the general public, the TA recipient's wishes would be respected.

\section{Information Related to the Administration of TA Projects}

29. Management will clarify that information dealing with the administration of a TA project will not be considered confidential, unless the TA recipient specifically indicates otherwise. In particular, given the high demand for this information and its importance for coordination among donors, this information would be made readily available to other TA providers and donors upon their request. In any event, Fund staff would not disclose information which third parties would regard as confidential (e.g., information on the terms of employment of a TA expert).

\section{Information Forming the Basis of TA Advice}

30. With regard to information provided to staff or generated by staff in the course of provision of $\mathrm{TA}$, the current practice of not making such information available will be continued. The likelihood that such information could be shared outside of Fund staff could undermine the Fund's ability to obtain all necessary data and information from country authorities. It could also affect the candor of discussions during a TA project's execution, whether they be in the form of exchanges with country authorities or internal deliberations among Fund staff. Further, experience has also shown that there is limited interest in this type of "input" information. The attention of Executive Directors, donors and other TA providers are more focused on the "outputs" of Fund TA instead, i.e., the actual TA reports.

\section{TA Reports}

31. Management intends to liberalize the $\mathbf{2 0 0 2}$ procedures with respect to dissemination of TA reports to Executive Directors. The consent for sharing TA reports with the Executive Board will be changed from the current requirement under the 2002 management procedures for explicit consent to consent on a no-objection basis (i.e., consent would be deemed given if a TA recipient does not object to such sharing within 60 days of transmittal to it of a TA report).

\section{Management also intends to liberalize the procedures for dissemination of TA} reports to donors and other TA providers who have a legitimate interest in the TA report. As discussed above, the sharing of such information is imperative for improved donor coordination. Above all, it allows the Fund to leverage its TA resources on related assistance that may be provided by other parties, and vice-versa. In view of these considerations, management intends to implement a rule whereby the consent of the TA recipient will be obtained on a no-objection basis. Specifically, the consent to share a TA report with donors and other TA providers who have a legitimate interest in such reports, would be deemed to have been given if a TA recipient does not object to such sharing within 
60 days from the date the report is transmitted to the TA recipient. ${ }^{52}$ With respect to any particular TA report, parties with a "legitimate interest" in receiving it shall include: (a) the donor who is financing the TA project out of which that report has been produced; and (b) a donor or TA provider engaging in related activities in the recipient country in the subject matter of the Fund's TA project. TA reports will be disseminated to donors and other TA providers on the explicit understanding that the receiving entity will respect the confidentiality of the reports.

33. As a complement to the wider dissemination of TA reports indicated above, the publication of TA reports will also be encouraged..$^{52}$ However, while broad publication of TA reports would be useful, it is not a key objective at this point. This is because the enhanced dissemination of TA reports (and related information) described above would sufficiently address the most important gaps in the sharing of TA information, particularly with respect to coordination with other TA providers and donors. Nevertheless, management remains mindful that the Executive Board has urged TA recipients to consent to the publication of TA reports on the Fund's external website in order to foster the wider sharing of lessons learned from the provision of Fund TA. In this regard, and in line with the proposal by the Managing Director's Task Force on TA, management will clarify that staff should proactively encourage TA recipients to agree to such publication. Members will be also encouraged to publish TA reports on their own websites.

\section{Finally, management intends to establish a liberal deletions and corrections procedure for TA reports that will be published. This is to ensure that, prior to a TA report's publication, sensitive information can be removed and that the views of the TA recipient and Fund staff are correctly characterized in the TA report. Specifically:}

- $\quad$ Prior to publication, deletions may be proposed by the TA recipient to management provided the relevant material is not already in the public domain and qualifies as (i): highly-market sensitive information, or (ii) policy intentions whose premature disclosure would seriously undermine the ability of the TA recipient to implement the proposed policy. Management will make the decisions on proposed deletions, and may take into consideration other factors in addition to the criteria mentioned above.

\footnotetext{
52 As noted in footnote 31, the Fund's current practice has been to treat members' consent for publication as revocable. It is management's intention to maintain this practice as a general rule, i.e., the member's consent can be withdrawn at any time prior to actual sharing of the TA report with other TA providers or donors with a legitimate interest in the information contained in the TA report. However, some donors require, as a condition for their funding a TA project, that TA report(s) produced in that project be disseminated to them. In these cases, management reserves the right to approve such a TA project only if the TA recipient provides its ex ante irrevocable consent to share all TA reports from that project with the applicable donor(s), as a condition for receiving the TA. Unlike the case described above, the TA recipient would not be able to withdraw its consent once TA provision has begun in such cases. The procedures for sharing TA reports with the World Bank described in paragraph 21 above would continue in place.
} 
- $\quad$ Before a TA report is published, (i) references to unpublished Fund documents, (ii) certain internal processes that are not disclosed to the public, including inquiries regarding possible misreporting and breaches of members' obligations, and (iii) discussions of a breach of obligation under Article VIII, Section 5 or misreporting that the Managing Director has proposed be treated as de minimis in nature as defined in paragraph 1 of Decision No. 13849 shall be removed from the document.

- $\quad$ Corrections may be proposed to resolve (i) data or typographical errors, (ii) factual mistakes, and (iii) mischaracterization of views expressed by the TA recipient.

- In order to maintain the intellectual integrity of the Fund's TA advice, and to preserve the substantive thrust of recommendations made in any TA report, management will withhold its consent to the publication of a TA report should management disagree with the deletions or corrections proposed by the TA recipient.

\section{RESOURCE IMPLICATIONS}

\section{Staff expect that implementation of the proposed measures will lead to a more} streamlined and efficient process for disclosure of TA information. In particular, moving to "no-objection" approach to obtaining members' consent to release TA information and reports will save time and effort expended by staff in trying to secure a response from country authorities. These savings are expected to off-set (partially or otherwise) the costs foreseen in processing deletions or corrections to TA reports prior to their dissemination. Additionally, some start-up costs would be incurred in the preparation of the staff operational guidance note detailing the new rules, an effort which staff estimates will require not more than 20 working days of time. 


\section{Dissemination of TA Reports-Policies and Practices of Some Other Organizations}

In preparing this paper, staff requested input from the following organizations on their respective policies and practices for the dissemination of TA reports: the World Bank, the African Development Bank (AfDB), the Asian Development Bank (AsDB), the European Bank for Reconstruction and Development (EBRD), and the Inter-American Development Bank (IADB). Responses received from the World Bank and the AsDB are summarized below; no replies were received from the AfDB, EBRD and IADB.

\section{World Bank}

The World Bank's disclosure policy ${ }^{53}$ does not address TA reports specifically. However, disclosure of TA reports is guided by the question of ownership rights over the report. In particular:

- $\quad$ TA reports which are prepared by Bank staff, or consultants hired by the Bank, are considered owned by the Bank. These reports are made publicly available after they are finalized or, where applicable, circulated to the Executive Board.

- $\quad$ TA reports are also prepared by consultants hired by member countries using Bank loans approved for that purpose. Such reports are considered owned by the country authorities, and their disclosure by the Bank is subject to the authorities' consent. However, notwithstanding these ownership rights, the Bank's disclosure policy recognizes that the Bank can share such reports with other international organizations, bilateral aid agencies, and similar parties who have a common interest in the relevant issue or subject.

- The public disclosure of certain types of TA reports is required as a condition for the approval of relevant Bank assistance. One example is environment assessment reports prepared by proposed borrowers, which are always made publicly available as a condition for Bank assistance.

- In all cases, the disclosure of documents/information will be subject to any explicit or implicit understandings that they will not be either: (a) disclosed outside of the Bank; or (b) disclosed without the consent of the source of the document/information.

\footnotetext{
${ }^{53}$ See http://go.worldbank.org/GMSLC6OP90.
} 


\section{$\underline{\text { Asian Development Bank }}$}

Comparable AsDB reports fall into two categories: (a) TA papers prepared at the appraisal/approval stage, containing some diagnostic material on the project; and (b) final consultants' reports produced under TA projects.

- $\quad$ As a general matter, both types of reports are posted on the AsDB website after approval/completion of the reports.

- Drafts of both types of reports may be given to in-country stakeholders or posted on the web for consultation purposes, if AsDB and the government/project sponsor determine it appropriate.

- Confidential information may be removed from both types of TA reports prior to dissemination. If an entire report is deemed confidential and therefore not to be disseminated, it must be clearly indicated as such and internal approval for dissemination sought according to specified procedures.

- $\quad$ Recipient country authorities are given the opportunity to object to the disclosure of reports only with respect to final consultant reports in "advisory technical assistance projects."

Full information on the AsDB's disclosure policies is available at:

http://adb.org/Documents/Handbooks/Disclosure/default.asp?p=disclose 
ATTACHMENT

Table

Summary of Current Fund Practice on Dissemination of TA Information
and Management's Intentions to Strengthen such Dissemination

\begin{tabular}{|c|c|c|}
\hline $\begin{array}{c}\text { Category of TA } \\
\text { Information }\end{array}$ & Fund's Current Practice & Management's Intentions \\
\hline $\begin{array}{c}\text { Information } \\
\text { Related to the } \\
\text { Fact of and } \\
\text { Subject-Matter of } \\
\text { TA }\end{array}$ & $\begin{array}{l}\text { Generally disclosed to the } \\
\text { Executive Board and parties outside } \\
\text { the Fund, unless the TA recipient } \\
\text { requests otherwise. }\end{array}$ & $\begin{array}{l}\text { Management will clarify that this } \\
\text { information will not be considered } \\
\text { confidential, unless the TA recipient } \\
\text { requests otherwise. Thus, it will be } \\
\text { ordinarily made available to the } \\
\text { Executive Directors, other TA providers, } \\
\text { donors and the general public. }\end{array}$ \\
\hline $\begin{array}{c}\text { Information } \\
\text { Related to the } \\
\text { Administration of } \\
\text { TA }\end{array}$ & $\begin{array}{l}\text { Not generally disclosed beyond } \\
\text { Fund staff. However, the Executive } \\
\text { Board receives reports on the } \\
\text { results of TA project evaluations as } \\
\text { part of the Fund's TA Evaluation } \\
\text { Program. Fund TA departments } \\
\text { have differing practices in sharing } \\
\text { this information with other TA } \\
\text { providers and donors. }{ }^{54}\end{array}$ & $\begin{array}{l}\text { Management will clarify that this } \\
\text { information will not be considered } \\
\text { confidential, unless the TA recipient } \\
\text { requests otherwise. In particular, this } \\
\text { information will be made readily } \\
\text { available to other TA providers and } \\
\text { donors upon their request. }\end{array}$ \\
\hline $\begin{array}{l}\text { Information } \\
\text { Forming the } \\
\text { Basis of TA } \\
\text { Advice }\end{array}$ & $\begin{array}{l}\text { Not currently shared with the } \\
\text { Executive Board or parties outside } \\
\text { the Fund. }\end{array}$ & No change proposed. \\
\hline TA Reports & $\begin{array}{l}\text { This type of information is } \\
\text { invariably treated } \\
\text { CONFIDENTIAL. Currently its } \\
\text { dissemination is limited to: Fund }\end{array}$ & $\begin{array}{l}\text { Management will clarify that the current } \\
\text { practices of dissemination of TA reports } \\
\text { with respect to Fund staff, the member's } \\
\text { Executive Director and the World Bank }\end{array}$ \\
\hline
\end{tabular}

\footnotetext{
${ }^{54}$ In some cases, for coordination purposes, Fund staff shares this information with other TA providers with due regard of any confidentiality considerations. In other cases, Fund staff has declined to make this information available.

${ }^{55}$ Fund staff will not disclose information that third parties would regard as confidential (e.g. information on the terms of employment of TA experts)
} 


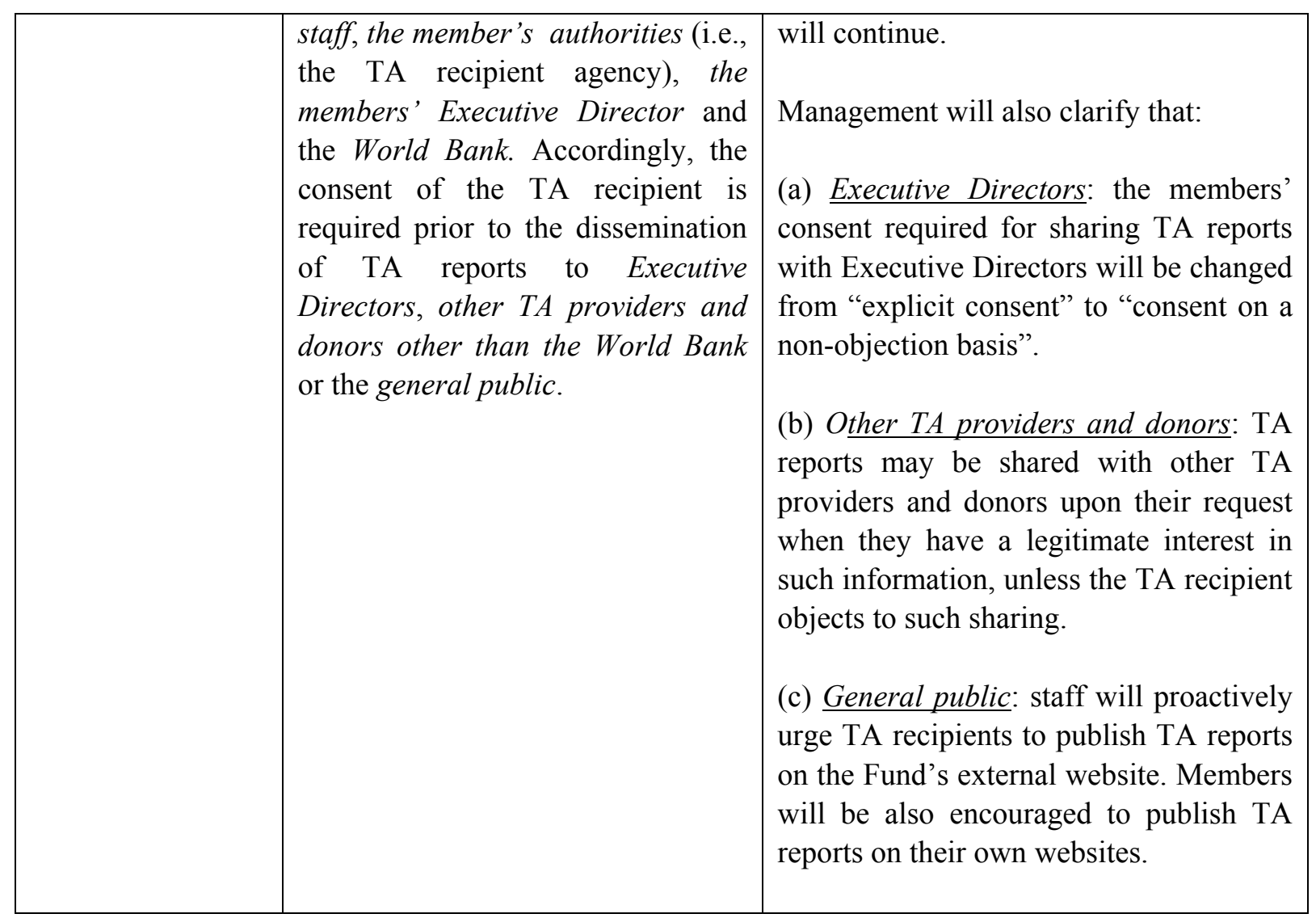

